\title{
Safety and effectiveness responses to etanercept for rheumatoid arthritis in Japan: a sub-analysis of a post-marketing surveillance study focusing on the duration of rheumatoid arthritis
}

\author{
Takao Koike • Masayoshi Harigai · Shigeko Inokuma • Naoki Ishiguro • \\ Junnosuke Ryu $\cdot$ Tsutomu Takeuchi $\cdot$ Yoshiya Tanaka $\cdot$ Hisashi Yamanaka • \\ Koichi Fujii · Takunari Yoshinaga $\cdot$ Bruce Freundlich $\cdot$ Michio Suzukawa
}

Received: 20 September 2010/Accepted: 30 December 2010/Published online: 16 February 2011

(C) The Author(s) 2011. This article is published with open access at Springerlink.com

\begin{abstract}
The aim is to investigate the relationship of duration of rheumatoid arthritis (RA) with safety and effectiveness of etanercept (ETN) in Japan. Post-marketing surveillance data for 7,099 patients treated with ETN were analyzed. Baseline characteristics, treatment effectiveness, incidence of adverse events (AEs), and serious AEs (SAEs) in relation to duration of RA were studied. At baseline, patients with RA for longer duration were older, weighed less, had more comorbidities, allergies, and corticosteroid use, but smoked less and had less morning stiffness. By 2-5 years with RA, more than half of the patients had advanced to Steinbrocker radiographic stage III or IV. Methotrexate (MTX) was the most commonly used pretreatment disease-modifying antirheumatic drug; however, concomitant MTX use and its dose were lower among patients with longer duration of RA. Remission rates
\end{abstract}

\section{T. Koike}

Hokkaido University Graduate School of Medicine,

Sapporo, Japan

M. Harigai

Tokyo Medical Dental University Graduate School,

Tokyo, Japan

S. Inokuma

Japanese Red Cross Medical Center, Tokyo, Japan

N. Ishiguro

Nagoya University Graduate School of Medicine,

Nagoya, Japan

J. Ryu

Nihon University School of Medicine, Tokyo, Japan

T. Takeuchi

Keio University, Tokyo, Japan
(26.6\%) were greatest among patients having RA for $<2$ years. Less AEs and SAEs were observed among patients with shorter duration of RA. These results suggest that RA treatment in Japan in the era pre-biologics may not have been adequate to control disease activity and prevent joint destruction. Patients with shorter duration of RA may have better physical status which allows the opportunity to treat more intensively putting a higher percentage of patients in remission and possibly decreasing exposure to SAEs.

Keywords Antirheumatic agents/adverse effects . Antirheumatic agents/therapeutic use - Arthritis, rheumatoid/drug therapy - Product surveillance, Postmarketing/statistics \& numerical data · Receptors, tumor necrosis factor/therapeutic use · Japan

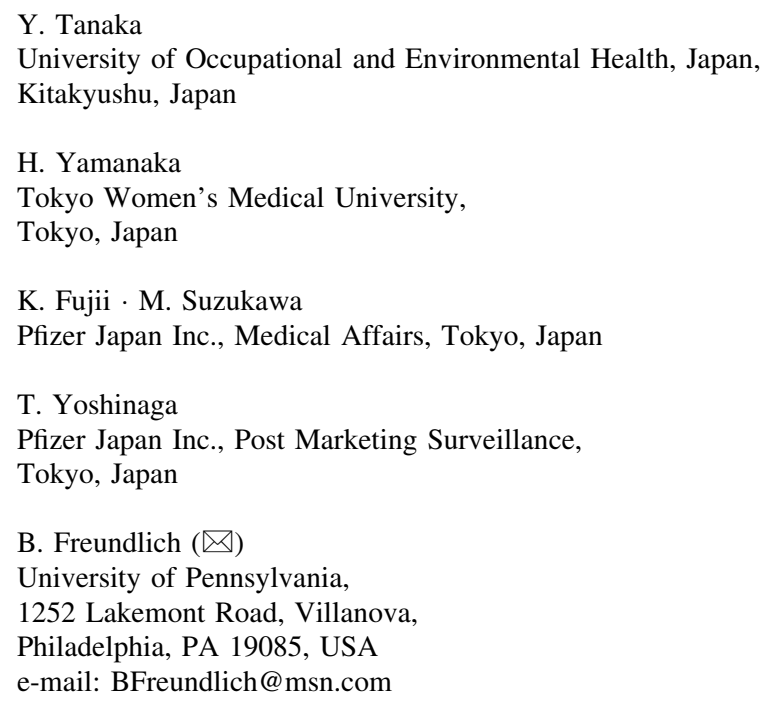




\section{Introduction}

The evolving strategy in the United States and Europe with regard to the control of rheumatoid arthritis (RA) disease activity is earlier treatment with disease-modifying agents; several guidelines support this strategy. Guidelines from the American College of Rheumatology (ACR) state that the ultimate goals in managing RA are to prevent or control joint damage, prevent loss of function, and decrease pain; initiation of disease-modifying antirheumatic drug (DMARD) therapy within 3 months of RA diagnosis is recommended [1]. Guidelines from the British Society of Rheumatology state that the recognition of early RA is a challenge and that the success of subsequent care is dependent on this early recognition [2]. Once definite RA has been established, British guidelines recommend that patients be placed on disease-modifying anti-rheumatic drug (DMARD) therapy as soon as possible; this is part of an overall aggressive strategy that includes escalating doses of medication, intra-articular steroid injections, parenteral methotrexate (MTX), and combination therapy [2]. In Europe, recommendations are even more aggressive; guidelines from the European League Against Rheumatism (EULAR) state that patients at risk of developing persistent or erosive arthritis should be started with DMARDs as early as possible, even if they have not yet filled established classification criteria for inflammatory rheumatological disease [3]. Despite this, it has been reported that between 2002 and 2005 in France, the conformity rate to EULAR guidelines was only 54\%, with just two-thirds of early RA patients treated with DMARDs at 6 months [4]. Similarly, in the United Kingdom and Ireland between 2002 and 2007, the median time to first DMARD treatment was 8 months after RA symptom onset [5].

In Japan, biologic response modifiers are recent options for RA disease management that may facilitate the prevention of joint damage and disease progression. Four such agents were available in Japan during the study period, etanercept (ETN), infliximab, adalimumab, and tocilizumab, but concerns exist that they may not be used early enough with a goal of achieving remission. Previous studies have reported that ETN is safe and efficacious when compared with other therapies including MTX, infliximab, adalimumab, anakinra, and other DMARDs [617]. Additionally, ETN safety and effectiveness have been confirmed in a recent meta-analysis [18]. However, since most of these studies involved relatively small numbers of patients, an in-depth analysis of the impact of patient profiles was either not possible or was generally limited in scope. The present post-marketing surveillance (PMS) study produced one of the largest databases available worldwide for RA patients treated with biologics and provided useful data about real world ETN use [19].
Results indicated that ETN is both efficacious and well tolerated as a treatment for RA patients in Japan [19]. The study involved a large number of RA patients receiving ETN, allowing in-depth analysis of a variety of patient profiles.

The objective of this study was to investigate the relationship between the duration of RA and the safety and effectiveness of ETN for RA in Japan. Patients from the PMS study [19] were subclassified based on the duration of RA and their characteristics were evaluated in relation to effectiveness and safety of ETN. Baseline patient PMS data also provided information about the burden of long-lasting RA and the types of DMARDs commonly used in Japan.

\section{Patients and methods}

The PMS study protocol was reviewed and approved by the Ministry of Health, Labor and Welfare. Patients' eligibility for treatment with ETN was based on the Japan College of Rheumatology (JCR) treatment guidelines [20]. Detailed methodology for the PMS study has been presented elsewhere [19]. Briefly, all RA patients who were treated with ETN in Japan between March 2005 and 2006 were monitored for 24 weeks. Registration and reporting were conducted centrally, and all patients had monthly assessments for AEs; all AEs and SAEs were recorded. Also recorded were age, gender, complications, Steinbrocker radiographic stage and functional class [21], duration of RA, smoking, previous and concomitant use of corticosteroids, concomitant use of MTX ( \pm the other DMARDs), and disease activity measured by the disease activity score (DAS28/4ESR). A dosage between 10 and $25 \mathrm{mg}$ of ETN was administered by subcutaneous injection, two times per week. EULAR response criteria and DAS28/4-ESR were used to evaluate treatment effectiveness. DAS28/4-ESR response levels were divided into 4 categories: $<2.6$ (remission), $\geq 2.6$ and $\leq 3.2$ (low disease activity), $>3.2$ and $\leq 5.1$ (moderate disease activity), and $>5.1$ (high disease activity).

\section{Statistical analysis}

Missing data were accounted for using last-observationcarried-forward methods, except for baseline values, which were not carried forward. The Cochran-Armitage exact test for trend (2-tailed) was used to determine whether there was a trend for AEs and good response and remission over duration of RA. Patients with RA for less than 2 years were identified as early RA based on previous studies [17, 22]. Chi-square tests were used to assess the association between pre-treatment of DMARD and duration of RA in baseline characteristics. Furthermore, multiple logistic 
regression models were applied to estimate odds ratio (OR) and $95 \%$ confidence intervals (CI) of remission and good EULAR response in relation to duration of RA after adjustment for major confounders (including age, sex, baseline DAS28/4-ESR, Steinbrocker functional class IV, duration of RA, history of infectious disease, history of tuberculosis, presence of any comorbidities, infliximab treatment experience, and concomitant DMARD use). We also used Cox proportional hazard models to estimate the influence of duration of RA on serious AEs after adjustment for major confounders. All statistical analyses were performed using SAS software, version 8.2, (SAS Institute, Inc., Cary, NC). Two-sided $P$ values of less than .05 were considered statistically significant.

\section{Results}

Patient characteristics, separated by duration of RA, are presented in Table 1. A total of 7,099 patients were treated with ETN and completed 24 weeks of treatment. A large majority $(81 \%, n=5,753)$ were women, and most patients $(79 \%, n=5,600)$ were over 50 years of age. The largest group of patients $(1,593)$ had RA for between 5 and 10 years, while the next largest group $(1,214)$ had RA for between 10 and 15 years. The smallest group of patients (707) had RA for less than 2 years. The patients with longer duration of RA were older and had more comorbidities. Fig. 1 shows the relationship between duration of RA and Steinbrocker functional class or radiographic stage. As one may expect, the percentage of patients with Steinbrocker class III and IV RA was higher with longer disease duration (Fig. 1a; $P<.001$, Cochran-Armitage trend test). Similarly, the percentage of patients with Steinbrocker radiographic stage III and IV RA was higher with longer duration (Fig. $1 \mathrm{~b} ; P<.001$, Cochran-Armitage trend test).

A large number of patients received prior DMARDs (Table 2). MTX was used by $65.8 \%$ of patients, salazosulfapyridine by $25.3 \%$ of patients, and bucillamine by

Table 1 Baseline characteristics of patients participating in post-marketing surveillance of etanercept in Japan according to duration of RA

\begin{tabular}{|c|c|c|c|c|c|c|c|c|c|}
\hline \multirow[t]{3}{*}{ Patient characteristic } & \multirow[t]{3}{*}{ Total, $N(\%)^{*}$} & \multicolumn{7}{|c|}{ Duration of RA (years) } & \multirow[t]{3}{*}{$P$-trend } \\
\hline & & \multicolumn{7}{|c|}{ Cases, $N(\%)^{*}$} & \\
\hline & & $<2$ & $2-5$ & $5-10$ & $10-15$ & $15-20$ & $>20$ & Unknown $^{\mathrm{b}}$ & \\
\hline \multicolumn{10}{|l|}{ Gender } \\
\hline Men & $1346(19.0)$ & $202(28.6)$ & $301(25.5)$ & $326(20.5)$ & $186(15.3)$ & $102(13.4)$ & $121(11.1)$ & $108(19.5)$ & \multirow[t]{2}{*}{$<.001$} \\
\hline Women & $5753(81.0)$ & $505(71.4)$ & $881(74.5)$ & $1267(79.5)$ & $1028(84.7)$ & $657(86.6)$ & $969(88.9)$ & $446(80.5)$ & \\
\hline Mean age (years) & 58.3 & 54.9 & 56.4 & 57.1 & 58.4 & 58.7 & 62.5 & 60.7 & $<.001$ \\
\hline Mean body weight (Kg) & 53.3 & 55.5 & 54.9 & 54.3 & 52.6 & 52.3 & 50.6 & 51.8 & $<.001$ \\
\hline Comorbidities & $4132(58.2)$ & $361(51.0)$ & $654(55.3)$ & $886(55.6)$ & $730(60.1)$ & $482(63.5)$ & $714(65.5)$ & $306(55.2)$ & $<.001$ \\
\hline Past history of lung disease ${ }^{c}$ & & $182(25.7)$ & $358(30.3)$ & $460(28.8)$ & $345(28.4)$ & $214(28.2)$ & $358(32.8)$ & $162(29.2)$ & ns \\
\hline Allergy & & $97(13.7)$ & $170(14.4)$ & $267(16.8)$ & $201(16.6)$ & $128(16.9)$ & $219(20.1)$ & $58(10.5)$ & $<.001$ \\
\hline Past history of smoking & $1029(14.5)$ & $154(21.8)$ & $242(20.8)$ & $261(16.4)$ & $149(12.3)$ & $78(10.3)$ & $92(8.4)$ & $54(9.8)$ & $<.001$ \\
\hline Previous steroid use & $6070(85.5)$ & $553(78.2)$ & $1020(86.3)$ & $1372(86.1)$ & $1042(85.8)$ & $675(88.9)$ & $951(87.4)$ & $459(82.9)$ & $<.001$ \\
\hline Mean number of years & & 1.0 & 2.5 & 5.3 & 7.5 & 9.8 & 11.0 & 3.5 & $<.001$ \\
\hline Morning stiffness (mins) & & 137.7 & 129.6 & 110.9 & 103.9 & 99.3 & 98.9 & 93.2 & $<.001$ \\
\hline DAS28/4-ESR (mean) & & 6.1 & 6.0 & 5.9 & 6.0 & 6.0 & 6.0 & 5.9 & ns \\
\hline Tender joints & & 10.1 & 9.8 & 9.7 & 10.0 & 9.7 & 10.0 & 10.3 & ns \\
\hline Swollen joints & & 9.0 & 8.8 & 8.8 & 9.3 & 9.2 & 9.3 & 9.1 & .009 \\
\hline Patients' VAS (mean/mm) & & 59.9 & 59.3 & 60.5 & 60.7 & 61.8 & 62.6 & 62.2 & .001 \\
\hline ESR $($ mean/mm) & & 65.3 & 61.7 & 60.1 & 58.3 & 60.0 & 62.8 & 60.3 & ns \\
\hline CRP (mean/mm) & & 4.4 & 3.8 & 3.8 & 3.6 & 3.6 & 3.5 & 3.9 & $<.001$ \\
\hline
\end{tabular}

* Value in parentheses is percent for all, unless otherwise specified with the patient characteristic

a $P$-trend: The Cochran-Armitage Trend test was used for variables expressed as percentages. The Jonckheere-Terpstra test was used for other variables

${ }^{\mathrm{b}}$ Unknown cases were excluded from the analysis

${ }^{c}$ Infectious pneumonia or chronic obstructive lung disease

$B M I$ body mass index, $C R P$ C-reactive protein, DAS disease activity score, ESR erythrocyte sedimentation rate, $M T X$ methotrexate, $R A$ rheumatoid arthritis, Patients' VAS Patients' visual analog scale 

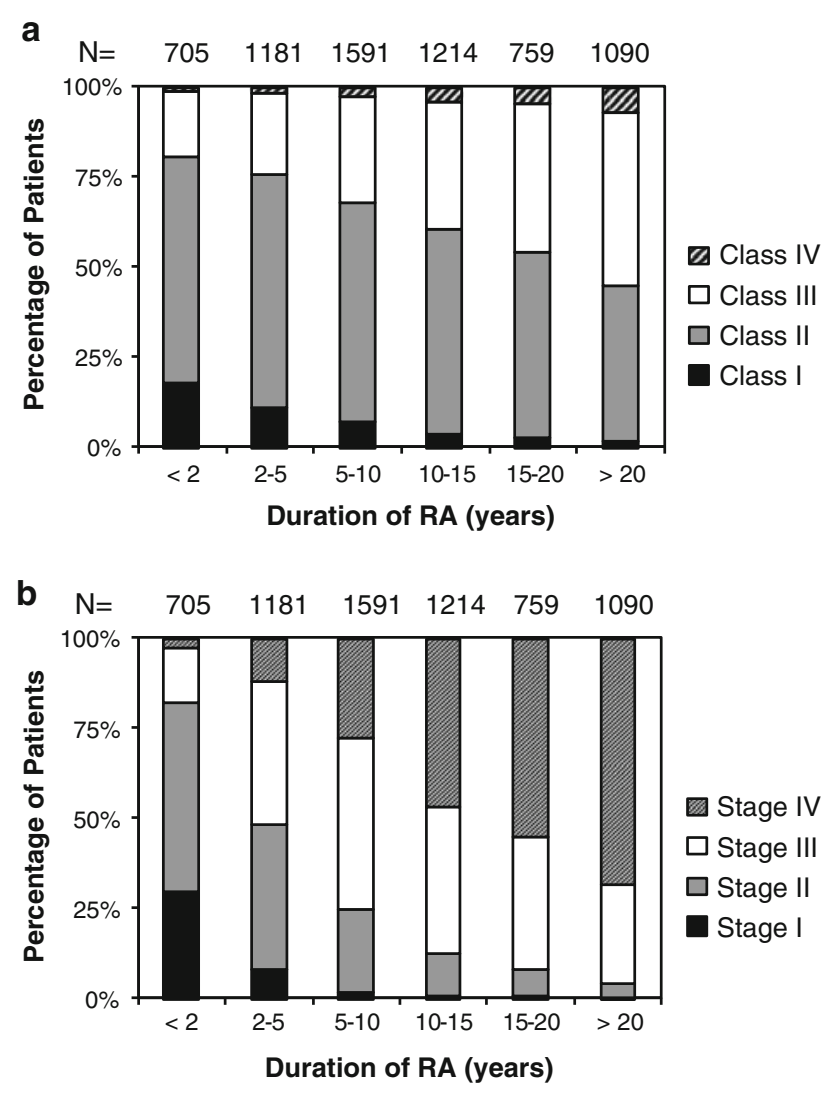

Fig. 1 A comparison of duration of rheumatoid arthritis and Steinbrocker functional class (a) and duration of rheumatoid arthritis and Steinbrocker stage (b) in patients receiving etanercept

$22 \%$ of patients, while infliximab was also used by $12.8 \%$ of patients (Table 2). It was noted that some DMARDs commonly used in United States and Europe (e.g., hydroxychloroquine) are not used in Japan because it is not approved in this country. In contrast, bucillamine, mizoribine, tacrolimus hydrate, and lobenzarit disodium, which are not approved in the United States or Europe, are used in Japanese RA patients. It was also shown that concomitant MTX use occurred more often in patients who had RA for shorter periods of time (Fig. 2a; $P<.001$, CochranArmitage trend test). Of patients who had RA for less than 2 years, $61.8 \%$ concomitantly used MTX while $41.8 \%$ of patients who had RA for more than 20 years used MTX. Figure $2 \mathrm{~b}$ shows the relationship between MTX, dose and duration of RA; the trend observed is a reduction in MTX dosage with longer duration of RA $(P<.001$, CochranArmitage trend test). For example, of patients having RA for less than 2 years, $46.7 \%$ received MTX at a dose of more than $8 \mathrm{mg}$ weekly, while $22.1 \%$ of patients who had RA for more than 20 years received more than $8 \mathrm{mg}$ weekly (the maximum dosage of the MTX label in Japan).

Over $80 \%$ of RA patients responded to ETN therapy, regardless of RA duration (Fig. 3a). Effectiveness of ETN
Table 2 Types of DMARDs previously used when switching to or adding etanercept

\begin{tabular}{llc}
\hline $\begin{array}{l}\text { Pre-treatment } \\
\text { DMARD class }\end{array}$ & Pre-treatment & $\begin{array}{c}\text { Number of } \\
\text { patients (\%) }\end{array}$ \\
\hline Biological DMARDs & Infliximab & $908(12.8)$ \\
& Etanercept & $108(1.5)$ \\
Non-biological DMARDs & Methotrexate & $4674(65.8)$ \\
& Azathioprine & $76(1.1)$ \\
& Leflunomide & $474(6.7)$ \\
& Cyclophosphamide & $38(.5)$ \\
& Mizoribine & $307(4.3)$ \\
& Tacrolimus hydrate & $218(3.1)$ \\
& Ciclosporin & $155(2.2)$ \\
& Salazosulfapyridine & $1799(25.3)$ \\
& Bucillamine & $1565(22.0)$ \\
& Sodium aurothio malate & $535(7.5)$ \\
& Auranofin & $187(2.6)$ \\
& Minocycline hydrochloride & $26(.4)$ \\
& D-penicillamine & $242(3.4)$ \\
& Lobenzarit disodium & $22(.3)$ \\
& Actarit & $316(4.5)$ \\
\hline
\end{tabular}

By at least 20 patients

$D M A R D$ disease-modifying antirheumatic drug
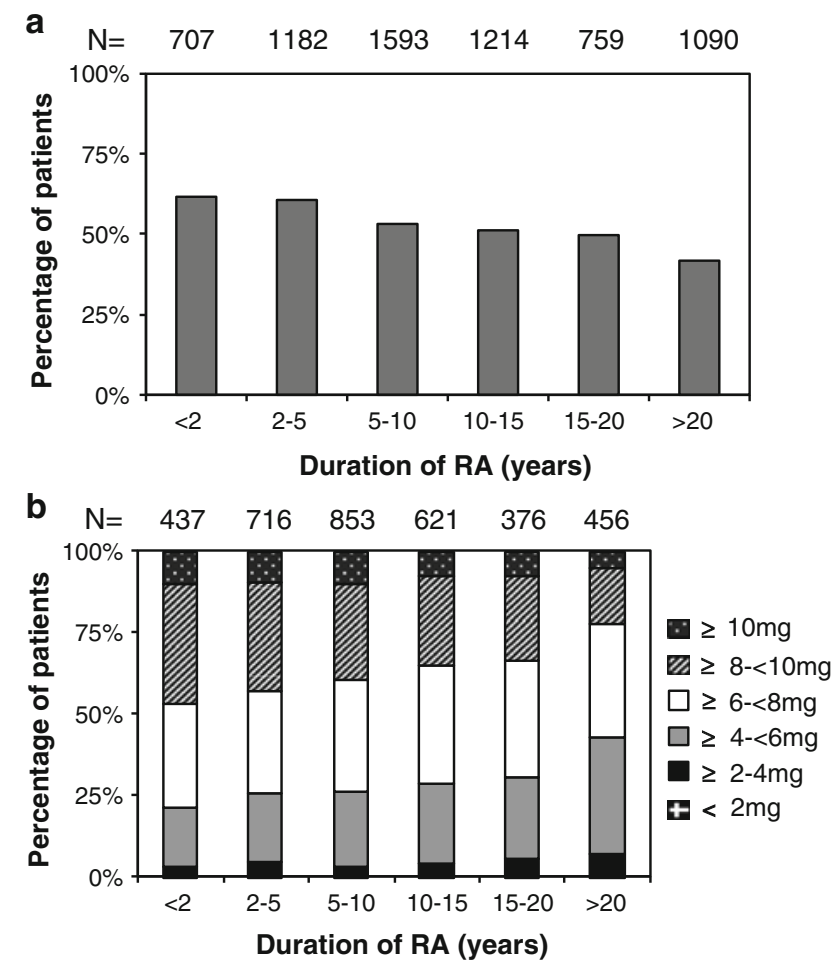

Fig. 2 Relationship between duration of rheumatoid arthritis and concomitant methotrexate use (weekly): Percentage of patients taking methotrexate at any dose (a), broken down by proportion using $2 \mathrm{mg}$ dose ranges $(\mathbf{b})$ 

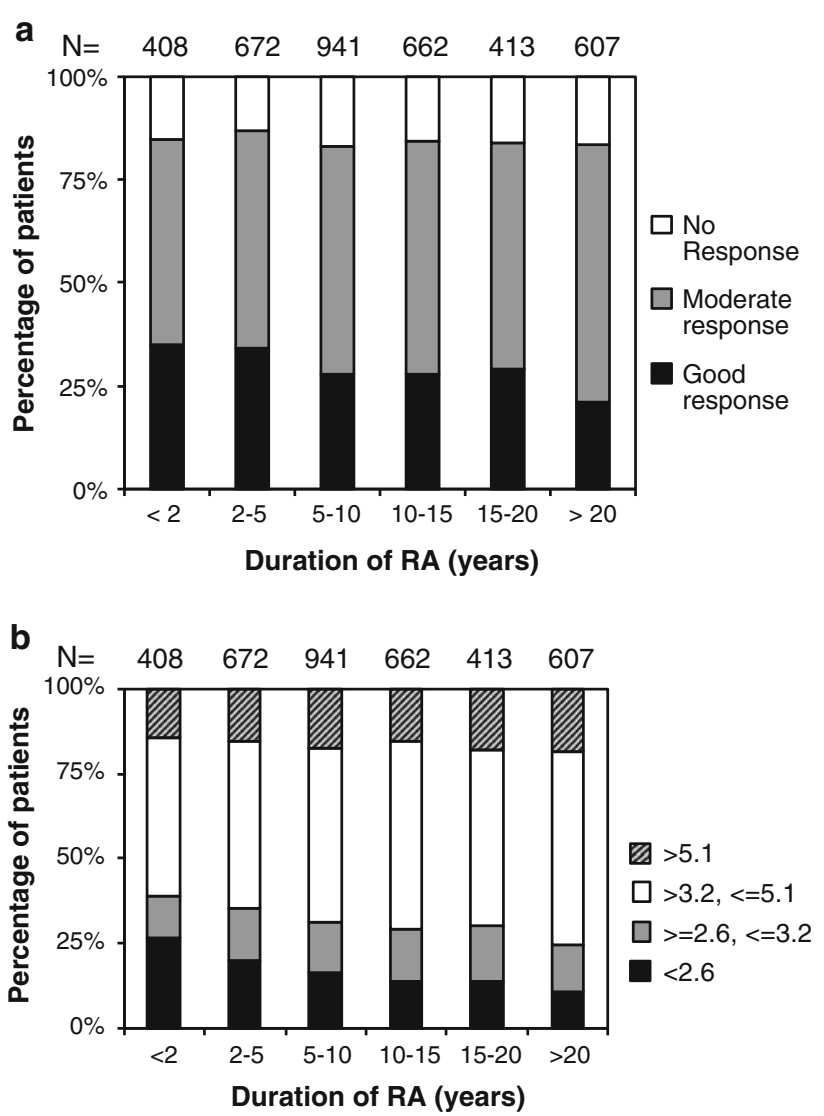

Fig. 3 European League Against Rheumatism (EULAR) response (a) and DAS28 remission rate as indicated by disease activity score (b) at 24 weeks in patients receiving etanercept: effectiveness based on duration of rheumatoid arthritis (last-observation-carried-forward method)

treatment based on a response rate of 'good' according to EULAR definitions was inversely related to duration of RA $(P<.001$, Cochran-Armitage trend test $)$. A significantly higher 'good response' rate was recorded for patients having RA less than 2 years $(36.1 \%)$ and between 2 and 5 years $(34.2 \%)$ compared to patients having RA for more than 20 years $(21.7 \%)$ (less than 2 years multivariate $\mathrm{OR}=1.548,95 \%$ CI $1.149,2.085 ; P=.004$; between 2 and 5 years multivariate $\mathrm{OR}=1.517,95 \%$ CI 1.161 , 1.983; $P=.002$ ). For patients having RA for more than 5 but less than 20 years, compared to patients having RA for more than 20 years, a trend toward a higher 'good response' rate was seen which was significant for the 15 to 20 year duration (multivariate $\mathrm{OR}=1.432,95 \%$ CI 1.062 , 1.93; $P=.019$ ). Of patients achieving a 'moderate response', the trend was opposite to that above, with the greatest percentage of patients (62\%) having RA for more than 20 years. Although 'good response' is lower as the duration of RA increases, the overall EULAR 'good plus moderate response' remained constant.
In addition to achieving the greatest 'good response' rate, patients having RA for duration less than 2 years also achieve the greatest remission rate $(26.2 \%$, defined as DAS28/4-ESR <2.6; Fig. 3b). A trend toward reduced numbers of patients achieving remission with longer duration of RA was observed $(P<.001$, Cochran-Armitage trend test). Remission was achieved by $20.3 \%$ of patients having RA for between 2 and 5 years, $16.0 \%$ of patients having RA for between 5 and 10 years, and $10.6 \%$ of patients having RA for more than 20 years. Compared with patients having RA for more than 20 years, those having RA for less than 5 years had a significant increase in achieving remission (less than 2 years multivariate $\mathrm{OR}=2.163$, 95\% CI 1.506, 3.107; $P<.001$; between 2 and 5 years multivariate $\mathrm{OR}=1.593,95 \%$ CI $1.132,2.241 ; P=.008)$. Among the adjustment factors, age $(<65$ years, OR $=$ $1.448,95 \%$ CI 1.164, $1.8 ; P=.001$ ), gender (male, OR = $1.365,95 \%$ CI $1.087,1.713 ; P=.007)$, moderate or lower disease activity $(<3.2-\leq 5.1, \mathrm{OR}=2.744,95 \%$ CI 2.246 , $3.352 ; P<.001 ; \leq 2.6-\leq 3.2, \mathrm{OR}=9.586,95 \%$ CI 4.828 , 19.03; $P<.001)$, Steinbrocker functional class $(\mathrm{I}+\mathrm{II}$, $\mathrm{OR}=1.878,95 \%$ CI $1.502,2.347 ; P<.001)$, no comorbidities (OR $=1.238,95 \%$ CI 1.027, $1.494 ; P=.025)$, and MTX use $(\mathrm{OR}=1.264,95 \%$ CI $1.012,1.579 ; P=.039)$ were associated with a significant increase in achieving remission using multiple logistic regression models.

Regarding safety, the rate of AEs and SAEs was lower among patients who had RA for shorter duration (Table 3, Cochran-Armitage p-trend <.001). For example, $31.8 \%$ of patients who had RA for less than 2 years experienced AEs while $37.9 \%$ of patients who had RA for more than 20 years experienced AEs. However, since other factors can affect the incidence of SAEs, the influence of the duration of RA on SAEs after adjustment for major confounders was estimated using Cox proportional hazard models; after adjustment, results showed no significant association between specific duration of RA and SAEs. Adjustment factors included age ( $>65$ years, HR $=1.476$, 95\% CI 1.231,1.770; $P<.001$ ), gender (male, HR = $1.346,95 \%$ CI 1.095, 1.656; $P=.005$ ), Steinbrocker functional class (III + IV, HR $=1.545,95 \%$ CI 1.287 , $1.854 ; P<.001)$, history of tuberculosis $(\mathrm{HR}=1.413$, 95\% CI 1.054, 1.894; $P=.021$ ), and presence of comorbidities $(\mathrm{HR}=3.020,95 \%$ CI $2.399,3.802 ; P<.001)$. Likewise, the incidence of serious infections was not affected by the duration of RA (Table 3). Interestingly, the incidence of SAEs at any given duration was lower, in many groups significantly, among patients with concomitant use of MTX (Table 3; lower half); using a Cox proportional hazard model, MTX use significantly decreased risk of SAE occurrence $(\mathrm{HR}=.625,95 \%$ CI $.505, .774$; $P<.001)$. 
Table 3 Safety results in patients in Japan receiving etanercept according to duration of RA

\begin{tabular}{|c|c|c|c|c|c|c|c|}
\hline \multirow[t]{2}{*}{ Duration of RA (years) } & \multicolumn{6}{|c|}{ Cases, $N(\%)$} & \multirow[t]{2}{*}{$P$-trend } \\
\hline & $<2$ & $2-5$ & $5-10$ & $10-15$ & $15-20$ & $>20$ & \\
\hline \multicolumn{8}{|l|}{ All ETN cases } \\
\hline Any AEs & $225(31.8)$ & $391(33.1)$ & $563(35.3)$ & 448 (36.9) & $324(42.7)$ & $413(37.9)$ & $<.001$ \\
\hline SAEs & $49(6.9)$ & $80(6.8)$ & $121(7.6)$ & $80(6.6)$ & $73(9.6)$ & $100(9.2)$ & .012 \\
\hline Death & 7 & 3 & 7 & 2 & 4 & 7 & \\
\hline Malignancy & 2 & 3 & 5 & 2 & 1 & 2 & \\
\hline Serious infections & $21(3.0)$ & $43(3.6)$ & $63(4.0)$ & $41(3.4)$ & $27(3.6)$ & $50(4.6)$ & ns \\
\hline \multicolumn{8}{|l|}{ ETN + MTX cases ${ }^{b}$} \\
\hline Any AEs & $117(26.8)$ & $238(33.2 *)$ & $293(34.3)$ & $240(38.7)$ & $153(40.7)$ & $160(35.1)$ & $<.001$ \\
\hline SAEs & $16(3.7 *)$ & $29(4.1 *)$ & $45\left(5.3^{*}\right)$ & $32(5.2)$ & $32(8.5)$ & $22\left(4.8^{*}\right)$ & .015 \\
\hline Death & 1 & 1 & 1 & 1 & 2 & 2 & \\
\hline Malignancy & 1 & 1 & 2 & 1 & 1 & 0 & \\
\hline Serious infections & $9(2.1)$ & $16(2.2)$ & $24(2.8)$ & $17(2.7)$ & $8(2.1)$ & $13(2.9)$ & ns \\
\hline
\end{tabular}

AEs adverse events, MTX methotrexate, $R A$ rheumatoid arthritis, SAEs serious adverse events

$* P<.05$ compared to All ETN cases (Fisher exact test)

a $P$-trend: Cochran-Armitage trend test

${ }^{\mathrm{b}}$ Patients with concomitant use of MTX ( \pm the other DMARDs)

\section{Discussion}

ETN was shown to be efficacious in more than $80 \%$ of the RA patients who were not successfully treated with prior DMARDs. Although other studies have reported that ETN is efficacious [7-13, 23-25], most of them involved relatively small numbers of patients so analysis of factors that can impact treatment outcome was either not possible or very limited. This study is unique in that it involved a large number of RA patients, allowing a more in-depth analysis of a variety of factors (e.g., duration of RA, functional class) with treatment outcome.

Maximum effectiveness has been observed in patients who are treated concomitantly with MTX [19], which was the DMARD most widely used concomitantly in this study. A unique feature of the treatment of RA in Japan is the use of domestically developed DMARDs such as bucillamine (D-penicillamine derivative), marketed only in Japan and Korea; it was the third most used DMARD in this investigation. The upper limit for dosing products also varies between the United States/Europe and Japan. Patients in this current study were treated with the locally available DMARDs by the discretion of the attending physicians; however, physical function deteriorated with duration of RA. This suggests that treatment in Japan in the era prebiologics may not have been adequate to control RA and that the use of newer therapies (biologics, combination therapies) may improve outcomes. Further investigation is recommended to evaluate the relationship between treatment strategy and long-term outcome of RA patients in Japan.
ETN was well tolerated for both early and advanced RA, and sub-analysis showed that ETN safety and effectiveness are maximized in patients with shorter duration of RA. Remission rate among early RA (less than 2 years after onset) was more than twice that of patients with 20 years of RA. Few studies have compared effects of ETN for patients with RA for short duration (early RA) versus longer duration within the same study; such analysis may have been limited by the size of the population being studied. Because the present PMS study evaluated a very large group of patients, dividing groups according to duration with RA and also by level of response was possible. Therefore, in addition to this study showing that response to ETN treatment was evident in over $80 \%$ of patients, significant trends emerged showing better response in those with RA for shorter duration than longer duration. This is in agreement with a study evaluating patient reported outcomes in RA patients assessed by the Health Assessment Questionnaire (HAQ); ETN therapy for patients with recent onset RA showed significantly greater improvement in disability measured by HAQ than for those with established RA [26].

Because structural damage and physical function worsen with duration of RA, these results agree with guidelines from the United States [1] and Europe [2, 3] which suggest early use of DMARD therapies to minimize the negative effects of RA on patients. It is also in agreement with results demonstrating greater clinical improvement of moderate compared to severe RA patients treated with ETN and/or MTX [27]. Possible reasons for the improved response in patients with a shorter-duration RA include that 
pathological mechanisms may differ between early and advanced RA; the percentage of patients taking concomitant MTX was higher in RA patients having RA for shorter duration; the dose of MTX used was higher in shorterduration RA patients; and longer duration of RA may cause extra-articular complications [7, 9, 28-30], which may narrow the choice of the treatment such as DMARDs/biologics combination therapy.

The current study demonstrated a good safety profile of ETN among Japanese RA patients in the real world. Overall incidence of AEs, SAEs, and serious infection was not higher compared to previous studies with ETN [7, 9, $10]$ or other TNF inhibitors $[6,12]$. However, the use of ETN for early RA patients may lead to even fewer adverse reactions. Interestingly, the incidence of SAEs was much lower among patients with concomitant MTX, and incidence of serious infection did not increase among concomitant MTX users with long duration of RA. However, further investigation of this point is required as patients who can tolerate MTX may have lower risk for both SAEs and serious infection. Cox proportional hazard models demonstrated that some confounding factors such as older age, advanced Steinbrocker functional class, and presence of comorbidities could be related to the higher incidence of SAEs among patients with longer duration of RA. In this study, patients with shorter duration of RA were younger, had fewer comorbidities, and had better physical function. A variety of factors including age, comorbidities, and concomitant DMARDs may contribute differently to the overall safety and effectiveness outcome among patients. However, starting aggressive treatment at an earlier time after the diagnosis of RA may provide the most efficient treatment to patients with less risk for SAEs and greater possibility for achieving remission, which may ultimately improve long-term quality of life.

Limitations of this study include that this was not a randomized controlled trial, patient profiles were different between groups, there was a relatively short observational period for a chronic disease ( 24 weeks), and that, following treatment initiation with ETN, changes in functional capacity and disease status using radiographic data were not available. Monitoring and analysis are ongoing and it will be interesting to compare long-term results with those of other studies [8].

\section{Conclusions}

This sub-analysis of the PMS study data established interesting links between duration of RA and safety/ effectiveness of ETN. We previously showed that ETN is both effective and well tolerated by Japanese RA patients, particularly with concomitant MTX use [19]. This analysis shows that more than $80 \%$ of patients responded to ETN treatment regardless of disease duration; however, a superior safety/effectiveness profile was observed among patients with shorter duration of RA. Continued analysis of longer-term findings will help to confirm these results and may further identify factors that affect ETN treatment effectiveness and safety and refine guidance for its use.

Acknowledgments The authors wish to acknowledge the contributions of the late Professor Kazuhiko Inoue, MD, PhD, who participated in this work. The authors wish to thank all participating physicians and registered patients. The Etanercept Post-Marketing Surveillance Committee of the Japan College of Rheumatology was created in response to a request for assistance from the Ministry of Health, Labor, and Welfare (MHLW) of Japan. The role of the committee is to provide independent advice to Wyeth $\mathrm{K}$. K. on the conduct of the Post-Marketing Surveillance Program mandated by the MHLW and on the results thereof. Participation on this committee is not compensated. This manuscript was prepared with the assistance of Joanne Foehl (previously of Pfizer Inc., Global Medical Affairs) and BioMedCom Consultants inc., Montreal, Canada. This study was sponsored by Wyeth (Wyeth was integrated into Pfizer in October 2009), and clinical fees were shared by Wyeth K. K. and Takeda Pharmaceutical Company Limited, Wyeth K. K.'s co-promotion partner for etanercept in Japan.

Role of the Sponsor Pursuant to the Pharmaceutical Affairs Law of Japan and the regulations promulgated there under, the Sponsor (Wyeth was integrated into Pfizer in October 2009) was required to conduct a PMS program as a condition for the marketing approval of etanercept. Wyeth was responsible for the development of the study protocol (with instruction from PMDA and advice from JCR PMS committee) and for the initial analysis of the data.

Conflict of interest Doctors T. Koike, M. Harigai, S. Inokuma, N. Ishiguro, J. Ryu, T. Takeuchi, Y. Tanaka, and H. Yamanaka are all members of the Etanercept Postmarketing Surveillance Committee of the Japan College of Rheumatology. It is the belief of the first author that this position does not constitute a Conflict of Interest. The doctors participated in the review and analysis of the PMS data in their capacity as Committee members and are so listed. The financial relationships of the authors with all manufacturers of biological products used in the management of RA are as follows. \#1 is a research grant to the institute to which they are affiliated, \#2 is a consulting fee, \#3 is membership of a speakers' bureau, \#4 is a fulltime employee, and \#5 is a previous employee of Pfizer. T. Koike, Abbott Japan, 1; Bristol-Myers Squibb, 1; Chugai Pharmaceutical Co. Ltd, 1; Eisai Co. Ltd, 1; Mitsubishi Tanabe Pharma, 1; Takeda Pharmaceutical Co. Ltd, 1; Wyeth KK, 1; Otsuka Pharmaceutical Co. Ltd, 2; Abbott Japan, 3; Bristol-Myers Squibb, 3; Chugai Pharmaceutical Co. Ltd, 3; Eisai Co. Ltd, 3; Mitsubishi Tanabe Pharma, 3; Takeda Pharmaceutical Co. Ltd, 3; Wyeth KK, 3; M. Harigai, Abbott Japan, 1; Bristol-Myers Squibb, 1; Chugai Pharmaceutical Co. Ltd, 1; Eisai Co. Ltd, 1; Mitsubishi Tanabe Pharma, 1; Pfizer Japan Inc., 1; Takeda Pharmaceutical Co. Ltd, 1; Abbott Japan, 2; Chugai Pharmaceutical Co. Ltd, 2; Mitsubishi Tanabe Pharma, 2; Abbott Japan, 3; Bristol-Myers Squibb, 3; Chugai Pharmaceutical Co. Ltd, 3; Eisai Co. Ltd, 3; Mitsubishi Tanabe Pharma, 3; Pfizer Japan Inc., 3; Takeda Pharmaceutical Co. Ltd, 3; S. Inokuma, None; N. Ishiguro, Abbott, 1; Chugai Pharmaceutical Co. Ltd, 1; Daiichi-Sankyo Pharmaceutical Co. Ltd, 1; Eisai Co. Ltd, 1; Mitsubishi Tanabe Pharma, 1; Takeda Pharmaceutical Co. Ltd, 1; Wyeth KK, 1; Abbott, 3; BristolMyers Squibb, 3; Chugai Pharmaceutical Co. Ltd, 3; Daiichi-Sankyo Pharmaceutical Co. Ltd, 3; Eisai Co. Ltd, 3; Mitsubishi Tanabe 
Pharma, 3; Takeda Pharmaceutical Co. Ltd, 3; Wyeth KK, 3; J. Ryu, None; T. Takeuchi, Bristol-Myers Squibb, 2; Mitsubishi Tanabe Pharma, 2; Novartis, 2; Abbott, 3; Chugai Pharmaceutical Co. Ltd, 3; Eisai Pharma, 3; Mitsubishi Tanabe Pharma, 3; Takeda Pharmaceutical Co. Ltd, 3; Y. Tanaka, Abbott, 1; Astellas Pharma Inc., 1; Chugai Pharmaceutical Co. Ltd, 1; Eisai Co. Ltd, 1; Mitsubishi Tanabe Pharma, 1; MSD KK, 1; Pfizer Inc., 1; Takeda Pharmaceutical Co. Ltd, 1; Mitsubishi Tanabe Pharma, 2; Abbott, 3; Astellas Pharma Inc., 3; Chugai Pharmaceutical Co. Ltd, 3; Eisai Co. Ltd, 3; Mitsubishi Tanabe Pharma, 3; Takeda Pharmaceutical Co. Ltd, 3; H. Yamanaka, Abbott Japan, 1; Chugai Pharmaceutical Co. Ltd, 1; Eisai Co. Ltd, 1; Mitsubishi Tanabe Pharma, 1; Takeda Pharmaceutical Co. Ltd, 1; Wyeth KK, 1; Abbott Japan, 3; Chugai Pharmaceutical Co. Ltd, 3; Eisai Co. Ltd, 3; Mitsubishi Tanabe Pharma, 3; Pfizer Japan Inc., 3; Takeda Pharmaceutical Co. Ltd, 3; Wyeth KK, 3; B. Freundlich, Pfizer Inc., 5; K. Fujii, Pfizer Japan Inc., 4; T. Yoshinaga,, Pfizer Japan Inc., 4; M. Suzukawa, Pfizer Japan Inc., 4.

Open Access This article is distributed under the terms of the Creative Commons Attribution Noncommercial License which permits any noncommercial use, distribution, and reproduction in any medium, provided the original author(s) and source are credited.

\section{References}

1. American College of Rheumatology Subcommittee on Rheumatoid Arthritis Guidelines (2002) Guidelines for the management of rheumatoid arthritis: 2002 update. Arthritis Rheum 46:328-346

2. Luqmani R, Hennell S, Estrach $\mathrm{C}$, Birrell $\mathrm{F}$, Bosworth A, Davenport G, Fokke C, Goodson N, Jeffreson P, Lamb E, Mohammed R, Oliver S, Stableford Z, Walsh D, Washbrook C, Webb F (2006) British Society for Rheumatology and british health professionals in Rheumatology guideline for the management of rheumatoid arthritis (the first two years). Rheumatology (Oxford) 45:1167-1169

3. Combe B, Landewe R, Lukas C, Bolosiu HD, Breedveld F, Dougados M, Emery P, Ferraccioli G, Hazes JM, Klareskog L, Machold K, Martin-Mola E, Nielsen H, Silman A, Smolen J, Yazici H (2007) EULAR recommendations for the management of early arthritis: report of a task force of the European Standing Committee for International Clinical Studies Including Therapeutics (ESCISIT). Ann Rheum Dis 66:34-45

4. Benhamou M, Rincheval N, Roy C, Foltz V, Rozenberg S, Sibilia J, Schaeverbeke T, Bourgeois P, Ravaud P, Fautrel B (2009) The gap between practice and guidelines in the choice of first-line disease modifying antirheumatic drug in early rheumatoid arthritis: results from the ESPOIR cohort. J Rheumatol 36:934-942

5. Kiely P, Williams R, Walsh D, Young A (2009) Contemporary patterns of care and disease activity outcome in early rheumatoid arthritis: the ERAN cohort. Rheumatology (Oxford) 48:57-60

6. Alonso-Ruiz A, Pijoan JI, Ansuategui E, Urkaregi A, Calabozo M, Quintana A (2008) Tumor necrosis factor alpha drugs in rheumatoid arthritis: systematic review and metaanalysis of efficacy and safety. BMC Musculoskelet Disord 9:52

7. Bathon JM, Martin RW, Fleischmann RM, Tesser JR, Schiff MH, Keystone EC, Genovese MC, Wasko MC, Moreland LW, Weaver AL, Markenson J, Finck BK (2000) A comparison of etanercept and methotrexate in patients with early rheumatoid arthritis. N Engl J Med 343:1586-1593

8. Dhillon S, Lyseng-Williamson KA, Scott LJ (2007) Etanercept: a review of its use in the management of rheumatoid arthritis. Drugs 67:1211-1241
9. Klareskog L, van der Heijde D, De Jager JP, Gough A, Kalden J, Malaise M, Martin ME, Pavelka K, Sany J, Settas L, Wajdula J, Pedersen R, Fatenejad S, Sanda M (2004) Therapeutic effect of the combination of etanercept and methotrexate compared with each treatment alone in patients with rheumatoid arthritis: double-blind randomised controlled trial. Lancet 363:675-681

10. van der Heijde D, Klareskog L, Singh A, Tornero J, Melo-Gomes J, Codreanu C, Pedersen R, Freundlich B, Fatenejad S (2006) Patient reported outcomes in a trial of combination therapy with etanercept and methotrexate for rheumatoid arthritis: the TEMPO trial. Ann Rheum Dis 65:328-334

11. Keystone EC, Schiff MH, Kremer JM, Kafka S, Lovy M, DeVries T, Burge DJ (2004) Once-weekly administration of $50 \mathrm{mg}$ etanercept in patients with active rheumatoid arthritis: results of a multicenter, randomized, double-blind, placebo-controlled trial. Arthritis Rheum 50:353-363

12. Levalampi T, Korpela M, Vuolteenaho K, Moilanen E (2008) Etanercept and adalimumab treatment in patients with rheumatoid arthritis and spondyloarthropathies in clinical practice: adverse events and other reasons leading to discontinuation of the treatment. Rheumatol Int 28:261-269

13. van Riel PL, Taggart AJ, Sany J, Gaubitz M, Nab HW, Pedersen R, Freundlich B, Macpeek D (2006) Efficacy and safety of combination etanercept and methotrexate versus etanercept alone in patients with rheumatoid arthritis with an inadequate response to methotrexate: the ADORE study. Ann Rheum Dis 65:1478-1483

14. Bingham CO III, Ince A, Haraoui B, Keystone EC, Chon Y, Baumgartner S (2009) Effectiveness and safety of etanercept in subjects with RA who have failed infliximab therapy: 16-week, open-label, observational study. Curr Med Res Opin 25:1131-1142

15. Hetland ML, Christensen IJ, Tarp U, Dreyer L, Hansen A, Hansen IT, Kollerup G, Linde L, Lindegaard HM, Poulsen UE, Schlemmer A, Jensen DV, Jensen S, Hostenkamp G, Ostergaard M (2010) Direct comparison of treatment responses, remission rates, and drug adherence in patients with rheumatoid arthritis treated with adalimumab, etanercept, or infliximab: results from eight years of surveillance of clinical practice in the nationwide Danish DANBIO registry. Arthritis Rheum 62:22-32

16. Emery P, Breedveld F, van der Heijde D, Ferraccioli G, Dougados M, Robertson D, Pedersen R, Koenig AS, Freundlich B (2010) Two-year clinical and radiographic results with combination etanercept-methotrexate therapy versus monotherapy in early rheumatoid arthritis: a two-year, double-blind, randomized study. Arthritis Rheum 62:674-682

17. Emery P, Breedveld FC, Hall S, Durez P, Chang DJ, Robertson D, Singh A, Pedersen RD, Koenig AS, Freundlich B (2008) Comparison of methotrexate monotherapy with a combination of methotrexate and etanercept in active, early, moderate to severe rheumatoid arthritis (COMET): a randomised, double-blind, parallel treatment trial. Lancet 372:375-382

18. Singh JA, Christensen R, Wells GA, Suarez-Almazor ME, Buchbinder R, Lopez-Olivo MA, Ghogomu ET, Tugwell P (2009) A network meta-analysis of randomized controlled trials of biologics for rheumatoid arthritis: a Cochrane overview. CMAJ 181:787-796

19. Koike T, Harigai M, Inokuma S, Inoue K, Ishiguro N, Ryu J, Takeuchi T, Tanaka Y, Yamanaka H, Fujii K, Freundlich B, Suzukawa M (2009) Postmarketing surveillance of the safety and effectiveness of etanercept in Japan. J Rheumatol 36:898-906

20. Miyasaka N, Takeuchi T, Eguchi K (2006) Guidelines for the proper use of etanercept in Japan. Mod Rheumatol 16:63-67

21. Steinbrocker O, Traeger CH, Batterman RC (1949) Therapeutic criteria in rheumatoid arthritis. JAMA 140:659-662

22. Goekoop-Ruiterman YP, Vries-Bouwstra JK, Allaart CF, van Zeben D, Kerstens PJ, Hazes JM, Zwinderman AH, Ronday HK, Han KH, Westedt ML, Gerards AH, van Groenendael JH, Lems 
WF, van Krugten MV, Breedveld FC, Dijkmans BA (2005) Clinical and radiographic outcomes of four different treatment strategies in patients with early rheumatoid arthritis (the BeSt study): a randomized, controlled trial. Arthritis Rheum 52:3381-3390

23. Listing J, Strangfeld A, Kary S, Rau R, von Hinueber U, Stoyanova-Scholz M, Gromnica-Ihle E, Antoni C, Herzer P, Kekow J, Schneider M, Zink A (2005) Infections in patients with rheumatoid arthritis treated with biologic agents. Arthritis Rheum 52:3403-3412

24. Weinblatt ME, Kremer JM, Bankhurst AD, Bulpitt KJ, Fleischmann RM, Fox RI, Jackson CG, Lange M, Burge DJ (1999) A trial of etanercept, a recombinant tumor necrosis factor receptor:Fc fusion protein, in patients with rheumatoid arthritis receiving methotrexate. N Engl J Med 340:253-259

25. Moreland LW, Schiff MH, Baumgartner SW, Tindall EA, Fleischmann RM, Bulpitt KJ, Weaver AL, Keystone EC, Furst DE, Mease PJ, Ruderman EM, Horwitz DA, Arkfeld DG, Garrison L, Burge DJ, Blosch CM, Lange ML, McDonnell ND, Weinblatt ME (1999) Etanercept therapy in rheumatoid arthritis. A randomized, controlled trial. Ann Intern Med 130:478-486
26. Baumgartner SW, Fleischmann RM, Moreland LW, Schiff MH, Markenson J, Whitmore JB (2004) Etanercept (Enbrel) in patients with rheumatoid arthritis with recent onset versus established disease: improvement in disability. J Rheumatol 31:1532-1537

27. Keystone E, Freundlich B, Schiff M, Li J, Hooper M (2009) Patients with moderate rheumatoid arthritis (RA) achieve better disease activity states with etanercept treatment than patients with severe RA. J Rheumatol 36:522-531

28. Pincus T, Callahan LF (1990) Remodeling the pyramid or remodeling the paradigms concerning rheumatoid arthritis-lessons from Hodgkin's disease and coronary artery disease. J Rheumatol 17:1582-1585

29. Wolfe F, Sharp JT (1998) Radiographic outcome of recent-onset rheumatoid arthritis: a 19-year study of radiographic progression. Arthritis Rheum 41:1571-1582

30. Rich E, Moreland LW, Alarcon GS (1999) Paucity of radiographic progression in rheumatoid arthritis treated with methotrexate as the first disease modifying antirheumatic drug. J Rheumatol 26:259-261 